\title{
UHF Wave Propagation Losses Beyond 40 Percent Fresnel Zone Radius in South-South, Nigeria
}

\author{
D. E. Bassey ${ }^{1}$, Aniefiok O. Akpan ${ }^{2}$, E Udoeno $^{3}$ \\ ${ }^{1}$ Electronics and Computer Technology Unit, Department of Physics, University of Calabar, Calabar, Nigeria
}

\begin{abstract}
Wireless signal deterioration in major sub-urban locations has been cause of concern to stakeholders. This study, therefore, under-take empirical study of the characteristics and issues of electromagnetic wave propagation under line-of-sight (LOS) signal transmission in Akwa Ibom State. The intent is to determine areas and causes of wireless signal fluctuation within 40 percent FZ level.. The investigation was restricted to line-of-sight (LOS) links at frequency range of $2.1 \mathrm{GHz}$ in the Southern part of Nigeria (lat. $4^{0} 32^{1}$ and $5^{0} 33^{1}$ North) and (long. $7^{0} 25^{1}$ and $\left.8^{0} 25^{1}\right)$, . Line-of-sight (LOS) signal measurements were carried out in randomly selected ten Local Government Councils in Akwa Ibom state. From the results obtained, the measured and calculated values of the Fresnel Zone clearance were in congruence. The variance between measured and calculated values ranged from $0.31 \mathrm{~m}$ to $1.88 \mathrm{~m}$ for 0.6 zones. Furthermore, from $0.22 \mathrm{~m}$ to $3.13 \mathrm{~m}$, for $1.0 \mathrm{FZ}$ number, and $0.26 \mathrm{~m}$ to $3.03 \mathrm{~m}$, for $2.0 \mathrm{FZ}$ number. Determined variation between the measured 1.0 FZ radius and 60 per cent no-obstruction radius at $1.0 \mathrm{FZ}$ number was carried out. This showed lost radius index range of $2.06 \mathrm{~m}$ to $9.12 \mathrm{~m}$. This analysis was done only for 1.0 zone number, since it was considered intermediate between the other two zones (0.6 and 2.0). The study further deduced that maximum signal strength was received between the ranges of 0.6 to 1.0 peak numbers for all locations. At 1.0 and 2.0 zone radius, the overall signal sent out were cut-off by some perceived obstructions along the line-of-sight path. The calculated and the measured path loss vary from 112.6dB to $134.2 d B$ and $109.5 d B$ to $130.2 d B$ respectively, while their differences vary from $2.3 d B$ to $4.0 d B$. The result further indicates that the strongest signal strength was established in Etinan at -80dB, and signal-to-noise ratio of $9 \mathrm{~dB}$ as the lowest. The root means square error (RMS) index for path loss range from $2.28 \mathrm{~dB}$ to $4.87 \mathrm{~dB}$. Comparatively, these results show a good agreement with earlier studies. The study inferred that urbanization, afforestation, etc., have contributed largely to attenuation of signal strength along these routes. Relevant recommendations for further studies were made relating to signal obstruction caused by afforestation and urbanization.
\end{abstract}

Keywords: Electromagnetic wave propagation, Fresnel Zone Clearance, Line-Of-Sight (LOS), Signal strength

\section{Introduction}

Electromagnetic wave propagates through the medium of the Ether. Its advent was seen as an enormous achievement in Physics. The radiation of this wave was made apparent by an Italian scientist, Gugliemo Marconi (1874-1937) in 19th century, when he made a public demonstration of his invention in Great Britain. Subsequently, he demonstrated the transmission of radio waves across the Atlantic Ocean [7].

This wave propagates through the space at a speed of $300,000,000 \mathrm{~m} / \mathrm{s}$. However, further studies have shown that the e-m waves suffer attenuation from natural and man-made structures along the part of propagation. These structures have the propensity to block the radio wave; thereby, causing weak signal to be received. This implies that the line-of-sight (LOS) of the radio waves has been blocked. The LOS, as applied to radio links, implies that the antennae at both end of the link can see each other (literally). Radio waves follow slightly curved path in the atmosphere, and so if there is a direct curved path between the antenna which does not pass through any obstacle, then, one still has radio LOS; an indication that the transmitting and the receiving antennae can see ,each other" within the radio horizon. Nevertheless, the effect of this LOS is usually experienced with higher frequency wave band like the VHF/ UHF: which is usually a major transmission mode used by many telecommunications service providers and innovators [1,2].

However, the aforementioned obstructions can penetrate remarkably into the Fresnel zone (FZ), being an elliptical shaped area of power created around the line-of-sight where radio waves spread through as they leave the transmitting antenna. To achieve a clear LOS, implies that maximum signal strength have been delivered; particularly for propagation under $2.4 \mathrm{GHz}$ frequency range. In transmitting within this radio frequency media, it is proper to take cognizance of the fact that $2.4 \mathrm{GHz}$ radio wave frequency are engrossed by water; similar to water found in leaves of trees. The path through which signal is expected to travel must be free and unobstructed, as well as the FZ which is spreading out several meters from the LOS [4,5]. To this end, this study seeks to ascertain the magnitude of loss experienced in the Fresnel zone; whether any obstacle penetrates the zone beyond 40 per cent in the five randomly selected Local Governments. As opined by Freeman (2009) [7,8], 20 percent of FZ obstruction initiates small signal deficit (loss) to the radio link. Above 40 percent obstacle, signal deficit (loss) can be significantly observed. The study, therefore, attempts to determine the level of signal deterioration at 40 percent FZ, and also analyze the characteristics of UHF wave propagation under this range.

\section{Radio Waves and Line-of-Sight Propagation}

Radio wave propagation across cities is greatly affected, depending on whether there is line-of-sight (LOS) between the transmitting and receiving antenna, or not. This is because the propagation characteristics of radio wave, such as path loss, fading and attenuation, do not only depend on the path distance and frequency, but also on the scattered angle, which also depends on the nature of obstruction to the EM wave. 


\section{International Journal of Science and Research (IJSR) \\ ISSN (Online): 2319-7064}

Index Copernicus Value (2013): 6.14 | Impact Factor (2014): 5.611

LOS as applied to radio links implies that the antenna at one end of the link can see each other (transmitting and the receiving antenna). Although, radio LOS suggests that a location of the antenna at one end of the link is able to see the other antenna (or future site) at the other end of the link. With unaided eye, one may still have LOS even though one cannot see the other end visually. This is because the radio horizon extends beyond the optical horizon [7]. Radio waves follow slightly curved path in the atmosphere, and so if there is a direct curved path between the antenna which does not pass through any obstacle, then one still has radio LOS.

Similarly, a non-line-of-sight (NLOS) link encounters obstacles such as buildings, trees and hills between the transmitting station and the receiving station. These include other sources of reflection such as ground. In cities, buildings, trees, road traffic, etc., often tend to block the ground reflection path. For long range paths, ground reflection is significant. Signal loss due to trees depends on the specific type of trees or the nature of the surface of the leaves (dry or fresh) [3,11]. Isolated trees are not usually a major problem, when compared to a dense forest zone. Attenuation of radio wave depends on the distance the signal must penetrate through the forest, and it increases with frequency. Depending on the type of obstacle, the transmitted signal may have multitude of paths known as multi-path (via reflection, refraction and diffraction) to the receiving station. Part of the signal will be detected with sufficient signal strength, while another part attenuated, or scattered as a result of these obstructions. Because the paths have different characteristics, the signal is received as multiple individual signals with varying amplitudes, delay, and strength; depending on the exact location of the receiver.

In the transmission of radio waves from the transmitter (TX) to the receiver $(\mathrm{RX})$, one must consider every activity that occurs when the wave is radiated from the transmitter to the receiver. Such activity includes the propagation properties of the TX and the RX. They include basically the characteristics of the radiator, such as gain, power, directivity (isotropic or anisotropic), and polarization effect. They also include attenuation due to free space. Meticulously, one can uphold that the Propagation of radio waves is dependent solely on the transmission properties and the boundary of the intersecting medium.

\subsection{Free Space Propagation and Fresnel Zone}

As mentioned above, LOS needs a clear path link between the operational antennas. Generally, FZ "is an ellipse-shaped area of power radiated between any two radio antennae". The path with which signal is expected to travel must be free and unobstructed, as well as the FZ which is spreading out several meters from the LOS [7].

Where:

$\mathrm{R}$ - Curved path of the first Fresnel zone $\mathrm{s}$ radius at the obstruction (in $\mathrm{Km}$ )

Ht - Height above the earth's surface at the transmitting antenna (in $\mathrm{Km}$ )

$\mathrm{Hr}$ - Height above the earthes surface at the receiving antenna (in $\mathrm{Km}$ )
$\mathrm{X}$ - Height of obstruction (in Km)

$\mathrm{h}$ - Earth curvature, from a flat plane between antennae, at the obstruction point.

d1 - Distance from transmitting antenna to the obstruction (in $\mathrm{Km})$

$\mathrm{d} 2$ - Distance from receiving antenna to the obstruction (in $\mathrm{Km})$

Dt - Total path distance between the TX and RX antennae (in $\mathrm{Km})$

$\mathrm{F}$ - Transmitted frequency in $(\mathrm{GHz})$

For first Fresnel zone

$$
R=\frac{15.8 \sqrt{d 1 *} d 2}{D t * f}(\text { in } K m)-------2.1
$$

For semi minor axis at mid-path

$$
R=\frac{15.8 \sqrt{\lambda} * D t}{D t * f}(\text { in } \mathrm{Km})-------2.2
$$

For other points

$$
R=\frac{31.6 \sqrt{d 1 * d 2}}{D t} \lambda(\text { in } \mathrm{Km})-------2.3
$$

For the broadest point of the Fresnel zone

$$
R=\frac{15.8 \sqrt{D t}}{4 * f}(\text { in } K m)-------2.4
$$

As stated in [6], Fresnel zone "is the area around the visual line-of-sight that the radio waves spread out into, after they leave the antenna". To achieve a clear LOS implies to achieve maximum signal strength, particularly for $2.4 \mathrm{GHz}$ frequency. In transmitting at $2.4 \mathrm{GHz}$ radio frequency, it is proper to take cognizance of the fact that $2.4 \mathrm{GHz}$ radio wave frequency can be engrossed (absorbed) by water. Studies indicate that at 20 per cent FZ, obstructions initiate small signal deficit (loss) to the radio link. Above 40 per cent obstacle, signal deficit (loss) can be significantly observed. If the radio signal is not obstructed, the waves are expected to travel directly from transmitter (TX) to receiver (RX). But if this is not achieved, part of the waves may be obstructed and cause this part to be reflected back to the RX under outof-phase mode. This phenomenon reduces the overall power of the signal received. Alternatively, this reflected wave can boast the overall power of the transmitted signal when it gets to the RX in-phase.

Augustus Fresnel has made available some formulae that can be used to determine where the zones are, and areas where the perceived obstruction may have caused the signal to cancel out or enhanced (in-phase or out-of-phase reflections between TX and RX) each other. He noted that [12], "obstacles in the first Fresnel zone will create signals with a path-length phase shift of 0 to 180 degrees. While in the second zone, they will be 180 to 360 degrees out of phase; and so on". However, odd number zones are believed to add-up to the signal power, while even number zones tend to cancel each other. This trend reduces the signal power.

Furthermore, any obstacle penetrating the FZ can be examined using the Fresnel zone clearance model. The first zone must be free from all perceived obstructions for maximum signal to be received. Basically, a tolerable measure of obstruction into the FZ can be permitted, since 


\section{International Journal of Science and Research (IJSR) \\ ISSN (Online): 2319-7064 \\ Index Copernicus Value (2013): 6.14 | Impact Factor (2014): 5.611}

the highest permissible obstruction into the FZ must not exceed 40 percent.

Fresnel zone analysis of a radio path needs to be carried out in order to check the clearance conditions. The earth bulge $\mathrm{H}$, which is the earthes surface height in meters, at a point $\mathrm{P}$ of the hop, compared to the chord between the end of TX and RX, can be calculated using $[7,8]$ :

$H=\frac{d 1 * d 2}{2 K r E} * 1000-------2.5$

Where:

$\mathrm{K}=$ the equivalent earth radius (EER) factor

$\mathrm{r}_{\mathrm{E}}=$ the radius of the Earth $=6,370 \mathrm{~km}$.

In a standard atmosphere, and if the whole first Fresnel zone is clear in a path profile, $\mathrm{K}=\mathrm{k}_{\mathrm{o}}=4 / 3$. Path profiles are very necessary when considering radio relay link and radio path. The basic path loss, $\mathrm{a}_{\mathrm{o}}$ is calculated using the equation: $A=92.4(d B)+20 \log D t(d B)+20 \log f(d B)---2.6$

\section{Research Method}

Akwa Ibom is one of Nigeriaes 36 states with a population of over 5 million people [10]. Six Local Government Areas selected on grounds of their topography, where the study was conducted are: Uyo, Afaha-Nsit, Nsit-Ubium, Eket, Ikot Ekpene and Abak. The investigations carried out include physical site survey, GPS measurements, calculations and plotting of Fresnel zone clearance, antenna location considerations and installations.

To carry out this study, under a clear line-of-sight transmission technique, certain components and parameters were inevitably required. A wireless link was established in all the selected study locations, and a physical survey carried out to determine if there are any impeding structures tending to obstruct useful signal around the study area. Appropriate logistics were also put in place.

The radio equipment selected and used for this work includes the following:

1) A global positioning system (GPS)

2) A parabolic antenna of Skynet network

3) Computer set

4) The transmitting antenna and receiving antenna

The receiving antenna installed at various locations was a $10 \mathrm{~dB}, 180^{\circ}$ fixed sectorized antenna for out-door monitoring. The under listed accessories were used during the installation of the antenna to establish effective connection, in addition to monitoring through the computer set.

1) RF coaxial cable (thin net cable LM400)

2) The wireless radio card for the receiving antenna

3)An indoor DC injector and outdoor amplifier for the fixed sectorizing antenna

4)Rolls of insulation tapes

5)PCMCIA adaptor for wireless card

6)Pig-tail connector for wireless card.

The transmitting antenna provided by Skynet is a parabolic antenna. Skynet is a wireless service provider that operates on a lease frequency of $2.3 \mathrm{GHz}$, and covers a distance of $64 \mathrm{~km}$. The channel frequency used in the study was $2.1 \mathrm{GHz}$. The gain of the antenna was $33.8 \mathrm{~dB}$, with effective coverage area of $3.5 \mathrm{~m}^{2}$, and efficiency of 58 per cent. The base station (Skynet) used the bus (base station unit) configuration manager to effectively monitor the signal and the data rate received at the receiver end.

\section{Results, Analyses and Discussion}

\subsection{Results}

Table 1 shows the path distance measured in kilometers, and the elevation of each of the locations considered. Uyo is a hinterland with heavy road traffic, level terrain, large number of cluster high-rising buildings and many telecommunications ${ }^{\text {ee }}$ companies. A path distance of $4.9 \mathrm{~km}$ was recorded at an elevation of $69.3 \mathrm{~m}$.

In Afaha-Nsit, a path distance of $23.6 \mathrm{~km}$ was obtained from Uyo at an elevation of $91.4 \mathrm{~m}$ above sea level. In this location, light road traffic was observed. Buildings were sparsely distributed, and there were few trees and few telecommunications ${ }^{\text {ee }}$ companies. It is also a hinterland. At Nsit Ubium, a path distance of $31.3 \mathrm{~km}$ was recorded from Uyo at an elevation of $74.3 \mathrm{~m}$ above sea level.

In order to establish a clear line-of-sight, measurements were taken from the point of possible obstructions; both from the transmitting station to the perceived obstruction, and from the perceived obstruction to the receiving station. The Fresnel zone clearance was calculated in order to obtain an unobstructed line-of-sight. Table 2 shows the distance of possible obstruction from the TX to the RX.

Table 1: Path distance from Uyo to other urban locations

\begin{tabular}{|c|c|c|}
\hline Locations & Path distance $(\mathrm{km})$ & Elevation $(\mathrm{m})$ \\
\hline Uyo & 4.9 & 69.3 \\
\hline Afaha-Nsit & 23.6 & 91.4 \\
\hline Nsit Ubium & 31.3 & 74.3 \\
\hline Eket & 42.4 & 35.4 \\
\hline Ikot Ekpene & 33.4 & 93.6 \\
\hline Abak & 26.8 & 96.6 \\
\hline
\end{tabular}

Table 2: Distance of obstruction point (from the transmitter to the obstacle, and from the obstacle to the receiver)

\begin{tabular}{|c|c|c|c|}
\hline Location & $\begin{array}{c}\text { Path } \\
\text { distance } \\
(\mathrm{km})\end{array}$ & $\begin{array}{c}\text { Distance from } \\
\text { the TX to the } \\
\text { obstacle, } d_{1}(\mathrm{~km})\end{array}$ & $\begin{array}{c}\text { Distance from } \\
\text { the obstacle to } \\
R X, d_{2}(\mathrm{~km})\end{array}$ \\
\hline Uyo & 4.9 & 2.7 & 2.2 \\
\hline Afaha- Nsit & 23.6 & 12.6 & 11 \\
\hline Nsit -Ubium & 31.3 & 20 & 11.3 \\
\hline Eket & 42.4 & 29.5 & 12.9 \\
\hline Ikot Ekpene & 33.4 & 16.2 & 17.1 \\
\hline Abak & 26.8 & 19.5 & 7.3 \\
\hline
\end{tabular}

\subsection{Discussions}

Table 3 shows the antenna height and the measured Fresnel zone peak for $0.6,1.0$ and 2.0 values for the selected locations. From observation from the study, peak values of 


\section{International Journal of Science and Research (IJSR) \\ ISSN (Online): 2319-7064 \\ Index Copernicus Value (2013): 6.14 | Impact Factor (2014): 5.611}

the Fresnel zone increased as the transmission path distance increased.

Table 3: Antenna height and measured Fresnel zone peaks

\begin{tabular}{|c|c|c|c|c|}
\hline Location & $\begin{array}{c}\text { Antenna } \\
\text { height }(\mathrm{m})\end{array}$ & $\begin{array}{c}\text { 0.6 Fresnel } \\
\text { zone peak } \\
(\mathrm{m})\end{array}$ & $\begin{array}{c}\text { 1.0 Fresnel } \\
\text { zone peak } \\
(\mathrm{m})\end{array}$ & $\begin{array}{c}2.0 \text { Fresnel } \\
\text { zone peak } \\
(\mathrm{m})\end{array}$ \\
\hline Uyo & 11.2 & 7.2 & 12 & 14.4 \\
\hline Afaha Nsit & 23.6 & 15.8 & 26.4 & 31.7 \\
\hline Nsit Ubium & 40.5 & 18.2 & 30.4 & 36.5 \\
\hline Eket & 14.5 & 21.2 & 35.4 & 42.5 \\
\hline Abak & 10.4 & 16.9 & 22.8 & 33.8 \\
\hline
\end{tabular}

The graph below shows the peak value for the calculated Fresnel zones for the selected locations

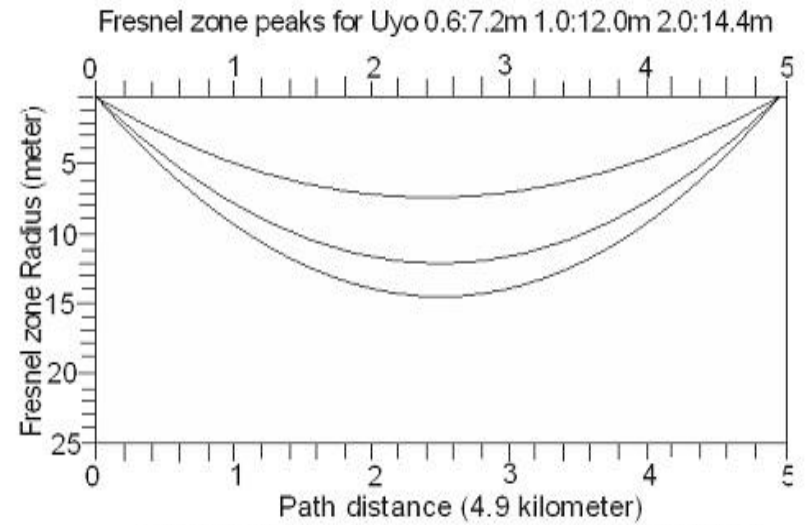

Fig. 9: Fresnel zone Clearance for $4.9 \mathrm{~km}$ distance

Fresnel zone peaks for Afaha Nsit 0.6:15.8m 1.0:26.8m 2.0:30.7m

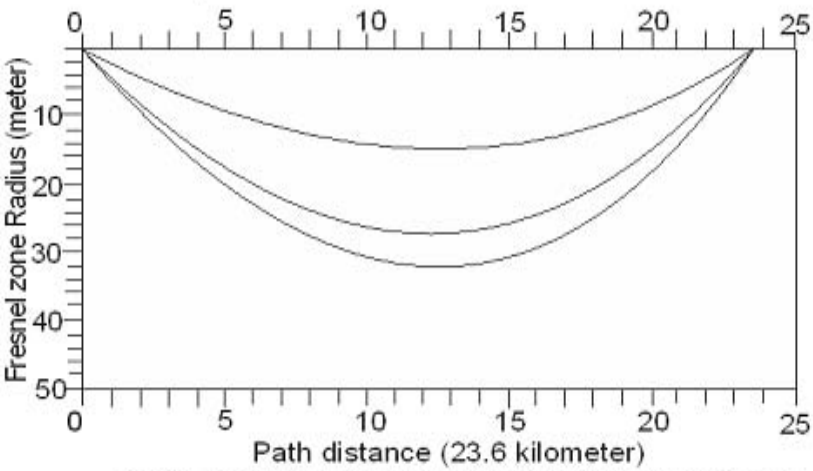

Fig.11: Fresnel zone Clearance for $23.6 \mathrm{~km}$ distance

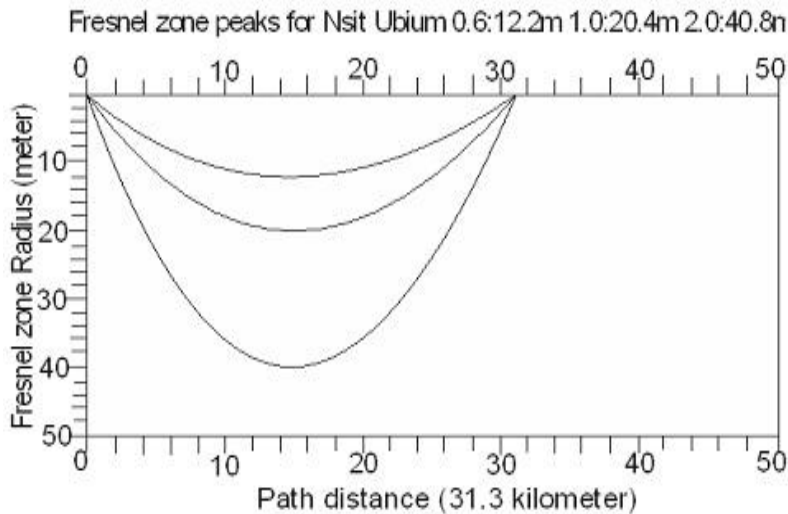

Fig.12: Fresnel zone Clearance for $31.3 \mathrm{~km}$ distance ।
Fresnel zone peaks for Eket 0.6:21.2m 1.0:35.4m 2.0:42.5m

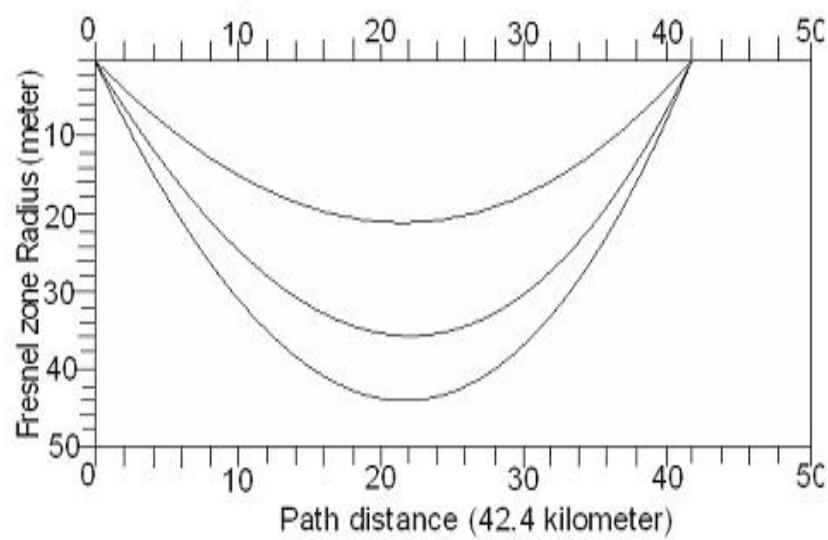

Fig.13: Fresnel zone Clearance for $42.4 \mathrm{~km}$ distance

Fresnel zane peaks for Abak 0.6:16.9m 1.0:22.8m 2.0:33.8m

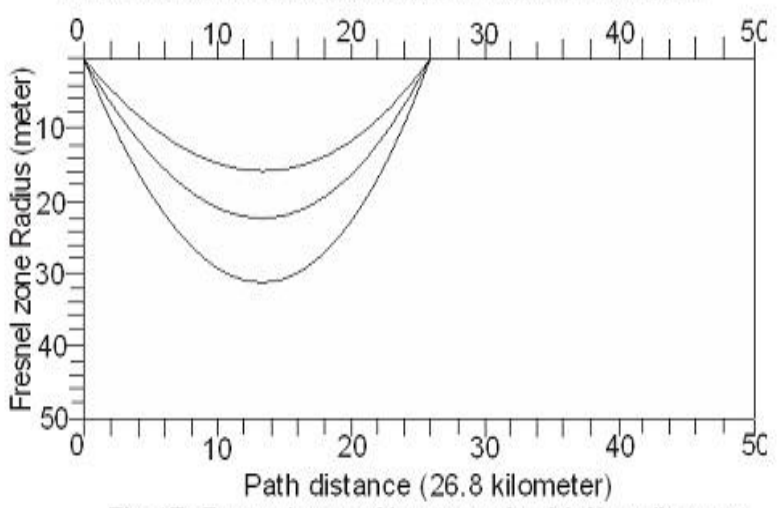

Fig.17: Fresnel zone Clearance for $26.8 \mathrm{~km}$ distance

Table 4 shows the peak values of the Fresnel zone calculated through the aid of a computer-based Fresnel zone calculator for $0.6,1.0$ and 2.0. Comparing Table 3 (peak values of measured Fresnel zone for 0.6, 1.0 and 2.0) and Table 4 (calculated values), it was observed that the measured values and the calculated values were in agreement with each other; except for minor errors which ranged between $0.2 \mathrm{~m}$ to $4 \mathrm{~m}$, for all the 5 locations.

Table 5 indicates the locations, the earth height and 60 per cent no obstruction radius [9]. From these values, 20 percent Fresnel zone blockage introduced minimal signal loss to the link. Beyond 40 percent blockage, signal loss became significant. The Table also displayed 60 percent without blockage for the various reception locations considered.

Table 4: Antenna height and calculated Fresnel Zone peak

\begin{tabular}{|c|c|c|c|c|}
\hline Location & $\begin{array}{c}\text { Antenna } \\
\text { height }(\mathrm{m})\end{array}$ & $\begin{array}{c}\text { 0.6 FZ peak } \\
(\mathrm{m})\end{array}$ & $\begin{array}{c}1.0 \mathrm{FZ} \\
\text { peak }(\mathrm{m})\end{array}$ & $\begin{array}{c}2.0 \mathrm{FZ} \text { peak } \\
(\mathrm{m})\end{array}$ \\
\hline Uyo & 11.2 & 7.8 & 13 & 15.6 \\
\hline Afaha Nsit & 23.6 & 17.4 & 29 & 34.8 \\
\hline Nsit Ubium & 40.5 & 19.2 & 32 & 38.4 \\
\hline Eket & 14.5 & 21.6 & 36 & 43.2 \\
\hline Abak & 10.4 & 16.8 & 28 & 33.6 \\
\hline
\end{tabular}




\section{International Journal of Science and Research (IJSR) \\ ISSN (Online): 2319-7064}

Index Copernicus Value (2013): 6.14 | Impact Factor (2014): 5.611

Table 5: Earth height and 60 per cent no-obstruction radius

\begin{tabular}{|c|c|c|}
\hline Locations & $\begin{array}{c}\text { Earth height } \\
\text { (mid-path })(\mathrm{m})\end{array}$ & $\begin{array}{c}\text { 60 per cent no- } \\
\text { obstruction radius }(\mathrm{m})\end{array}$ \\
\hline Uyo & 0.47 & 10 \\
\hline Afaha Nsit & 10.9 & 22 \\
\hline Nsit Ubium & 19.2 & 25 \\
\hline Eket & 35.2 & 23 \\
\hline Abak & 14 & 21 \\
\hline
\end{tabular}

Table 6 shows that at Uyo, signal within $10.0 \mathrm{~m}$ radius from the line-of-sight was received strongly at the earth's height of $0.47 \mathrm{~m}$. The total signal along the line of sight, from the transmitting antenna was within $12.0 \mathrm{~m}$ range (i.e. 1.0 peak value). At Afaha Nsit, Nsit Ubium and Eket, the total signal radius which along the line of sight from the antenna was within $26.4 \mathrm{~m}, 30.4 \mathrm{~m}$ and $35.4 \mathrm{~m}$; while the 60 percent no obstruction signal received was within $22.0 \mathrm{~m}, 25.0 \mathrm{~m}$ and $23.0 \mathrm{~m}$ at earth's height of $10.9 \mathrm{~m}, 19.2 \mathrm{~m}$ and 35.2 , respectively. A fraction of $4.4 \mathrm{~m}, 5.4 \mathrm{~m}$ and $7.4 \mathrm{~m}$ range were lost due to obstruction.

Optimally, at Abak, the total signal radius sent out from the transmitting antenna was at $28.2 \mathrm{~m}$. The 60 percent no obstruction signal was received at $21.0 \mathrm{~m}$ within the earth 's height of $14.0 \mathrm{~m}$, while a fraction of $7.2 \mathrm{~m}$ signal radius were lost to obstruction.

Table 6: Earth's height, 1.0 measured Fresnel zone radius, 60 per cent no-obstruction radius and the Lost Fresnel zone peak radius

\begin{tabular}{|c|c|c|c|c|}
\hline Location & $\begin{array}{c}\text { Earth } \\
\text { height }(\mathrm{m})\end{array}$ & $\begin{array}{c}\text { 1.0 measured } \\
\text { Fresnel zone } \\
(\mathrm{m})\end{array}$ & $\begin{array}{c}\text { 60 percent no } \\
\text { obstruction }(\mathrm{m})\end{array}$ & $\begin{array}{c}\text { Lost } \\
\text { radius } \\
(\mathrm{m})\end{array}$ \\
\hline Uyo & 0.47 & 12 & 10 & 2 \\
\hline Afaha Nsit & 10.92 & 26.48 & 22 & 4.48 \\
\hline Nsit Ubium & 19.2 & 30.49 & 25 & 5.49 \\
\hline Eket & 35.23 & 35.49 & 28 & 5.49 \\
\hline Abak & 14.08 & 28.22 & 21 & 7.22 \\
\hline
\end{tabular}

To this end, the highest Fresnel zone radius lost due to obstruction was at Abak, with $7.22 \mathrm{~m}$ lost radius. Next were Eket and Nsit-Ubium, with lost radius value of $5.49 \mathrm{~m}$. The location with the lowest lost value was Uyo $(2.06 \mathrm{~m})$; followed by Afaha Nsit with $4.48 \mathrm{~m}$. These point to the fact that as path distance increases, signal lost increased (Table $7)$.

However, one can conveniently say that 2.0 and 1.0 Fresnel peak value were severely obstructed or lost to obstruction in that the 1.0 peak numbers were beyond the 60 per cent noobstruction radii for all the locations. Maximum signal were received at 0.6 Fresnel zone radii which was below the 60 per cent no-obstruction radii for all locations. This deduction was adduced from the analysis in Table 11 above. However, nothing was observed to have intercepted the signals in the 0.6 peak radii, but at least 60 percent of the transmitted signal was received at this radii.

Table 7 below shows the path distance measured in kilometers, as well as attenuation of signal free from all perceived obstructions was obtained using equation 2.7. It was observed in Table 7 below that attenuation increased as the path link increased.

Table 7: Path distance and attenuation from free space

\begin{tabular}{|c|c|c|}
\hline Location & Path distance $(\mathrm{km})$ & Attenuation $A_{0}(\mathrm{~dB})$ \\
\hline Uyo & 4.9 & 112.6 \\
\hline Afaha Nsit & 23.6 & 126.3 \\
\hline Nsit Ubium & 31.3 & 128.7 \\
\hline Eket & 42.4 & 131.3 \\
\hline Abak & 26.8 & 127.4 \\
\hline
\end{tabular}

To accord credence to the claim that increase in path distance is proportional to the rate of attenuation, it is evidence that Eket had a relatively long distance which resulted to relatively high rate of attenuation. Consequently, this led to poor signal reception at these locations.

Table 8: Signal strength and Signal-to-noise ratio (SNR) values.

\begin{tabular}{|c|c|c|c|}
\hline \multirow[t]{2}{*}{ Location } & \multirow{2}{*}{$\begin{array}{l}\text { Signal } \\
\text { strength } \\
(d B)\end{array}$} & Received signal & to noise ratio $(\mathrm{dB})$ \\
\hline & & $\begin{array}{l}\text { Lowest signal } \\
\text { value }(d B)\end{array}$ & $\begin{array}{l}\text { Highest signal value } \\
(d B)\end{array}$ \\
\hline Uyo & -83 & 11 & 17 \\
\hline Afaha Nist & -81 & 10 & 17 \\
\hline Nsit Ubium & -82 & 10 & 16 \\
\hline Eket & -87 & 13 & 18 \\
\hline Abak & -84 & 11 & 17 \\
\hline
\end{tabular}

Table 8 shows the value obtained from wireless client manager. The table showed that the signal strength was highest at Afaha-Nsit with $-81 \mathrm{~dB}$ and with the lowest signalto-noise ratio (SNR) value of $10 \mathrm{~dB}$ and the highest at $17 \mathrm{~dB}$, Uyo had a value of $-83 \mathrm{~dB}$. But Uyo had a better signal-tonoise ratio of $11 \mathrm{~dB}$ for the lowest and $18 \mathrm{~dB}$ for the highest. Nsit Ubium established good signal strength of --82dB with SNR of $10 \mathrm{~dB}$ for the highest and $16 \mathrm{~dB}$ for the lowest value. The weakest signal strength of $-87 \mathrm{~dB}$ was recorded at Eket followed by Abak with signal strength of $-84 \mathrm{~dB}$.

Though Afaha-Nsit was classified as an urban area with few clutters of high buildings, few trees, light road traffic along the path of line-of-sight, it gave strong signal strength of $81 \mathrm{~dB}$, and a good signal-to-noise ratio. A place like Uyo that was expected to have the best signal strength, and signal-tonoise, due to its proximity to the transmitting station came out third in the Table. This is attributed to clusters of high rising buildings in the capital city; impeding free passage of signal. Interference from other radio masts erected by other telecommunications companies was another major problem in Uyo; as some of these antennas made use of both LOS and NLOS to transmit signal to their clients. The position of Eket was not surprising, because, it was classified as an urban area with quite a number of cluttered tall trees and buildings along the path of LOS, capable of reducing or obstructing the signal propagation. Moreover, there was no repeater station between Uyo and Eket to re-energize the radio signal.

\section{Conclusion}

From the results of the survey conducted in this study, lineof-sight was established in all the five (5) locations (Uyo, Afaha Nsit, Nsit Ubium, Eket and Abak). Though, better 
line-of-sight was established at Afaha-Nsit; which yielded $81 \mathrm{~dB}$ signal strength and lost radii of $4.48 \mathrm{~m}$. On the other hand, Eket established a very poor line-of-sight with signal strength of $-87 \mathrm{~dB}$.

From these results, obstruction like trees in places like Eket and Abak, if allowed to grow taller could greatly affect a clear LOS. The result achieved in this location was better because of painstaking variation of the receiving antenna. In addition, interference from other transmitting stations like Globacom, Etisalat, Airtel and MTN contributed in obstructing signal from the transmitting location. Also, low strength of signal in some of these locations may be attributed to attenuation; since attenuation increases as signal path increases. These scenarios made fading inevitable.

\section{References}

[1] Biddulph, D. (1993). VHF/UHF Hand book, RSGB

[2] Bullington K. (1999). "Radio Propagation for Vehicular Communication" IEEE transactions on vehicular technology, 26(4), p24

[3] Carter, D., (2013), Spread Spectrum: Regulation in Telecommunication. Retrieved October 16, 2013 from www.google.com/radiofrequencies/

[4] Christopher, H. (2008). Essential of Radio Wave Propagation U.K: Cambridge University Press.

[5] Collins, S. (2000). Principle of Radio Propagation. New York: Wiley and Sons.

[6] Crane, R.K. (1976) "Refraction Effect in the Natural Atmosphere: Methods of Experimental Physics, Astrophysics, Parr B. Radio Telescope" (M.L. Meeks, CD), 12 New York: Academic Press P.200.

[7] Fraser, W (2003). Telecommunication. New Delhi: CBS Publisher and Distributors.

[8] Frederick, H. (2002). GPS Communication. England United Business Media.

[9] Freeman R. L. (2009) "Wireless supporting information/test \& measurement technical note". Retrieved January 19, 2014 from http://www.spectracomcorp.com

[10] Government of Akwa Ibom State (2008) "Information about Akwa Ibom State" retrieved Feburary 13, 2014 from http://www.google.com/akwaibom

[11] Hall et al (1996). Effects of the Troposphere on Radio Communication: Peter Peregrinus Ltd; I (2).pp69-74.

[12] Hall, M.P. Howitt, M.T. and Barday, L.W. (1979). Propagation of Radio Wave. London: Short run Press Ltd. 